\title{
Godin Benoît (2020) The Idea of Technological Innovation: A Brief Alternative History. Cheltenham: Edward Elgar Publishing. 208 pages. ISBN: 9781839104015.
}

\author{
Auke Pols \\ auke.pols@wur.nl
}

Science and technology are often treated as inextricably linked, whether we talk about Science, Technology and Innovation policies, Responsible Research and Innovation or our own field of Science and Technology Studies. It is this link that is challenged by Godin in his historiography of the concept of technological innovation. Focusing on developments in the UK and the US from the Second World War onwards, he provides ample evidence that technological innovation is not only more than applied science, but also "that practitioners (...) have been pioneering theorists of technological innovation, beginning in the 1950s. It is the practitioners' view that scholars articulated later on and theorized about" (p. 3).

The book is detailed and rigorous in supporting this claim throughout. Godin analyses a rich collection of policy documents and consultancy reports from the 1950s to the present day to support his thesis. He systematically investigates the definition of technological innovation these documents use to identify (overlapping) phases of how technological innovation has been conceptualised: as science applied, as an outcome, as a process, and as a system. The final chapters of the book show how these different conceptualisations have affected innovation policy in the past and today. This systematic investigation paints a picture of technological innovation as a field of practice with its own actors, policy recommendations and trends. Scholars are shown to have contributed to this field not by laying its founda- tions, but by explaining and articulating extant views and developments. Furthermore, Godin's systematic investigation into the idea of technological innovation allows him to make meaningful connections to topics outside the scope of the book, such as earlier trends that paved the way for the idea (e.g. fears of unemployment due to industrialisation in the 1920s) and, more recently, a proliferation of non-technological innovation concepts (inclusive, responsible, sustainable...).

Some insights from the book that I found particularly helpful as an innovation researcher concerned Godin's focus on organisations rather than nation-states, his emphasis on the driving force of economic growth and competitiveness as innovation policy goals, and the consequences of the innovation discourse on the relationship between science and innovation.

First, Godin does not focus on nation-states and their policies, but on the institutions within and behind them and their influence. This allows him to identify a number of actors that have strongly shaped policies in their own nation and beyond. The US Department of Commerce is an important one, but particularly the OECD emerges as an organisation influential with respect to the innovation policies of its members. Its role certainly seems to warrant greater attention by innovation scholars.

Second, a stark contrast emerges between discourses and policies on technological innovation, which are constantly in flux, and the monolithic economic policy goals of growth and 
competitiveness that drive them. Replacing 'full employment' as economic policy focus after the Second World War (p. 22), economic growth and competitiveness have remained in place ever since. The book documents almost no reflection among practitioners on the importance of those goals, only on how they could best be achieved. Given public controversies over scientific and technological developments at the time, one wonders if those policy goals were never challenged, or whether challenges were brought forward but dismissed.

Science and science policy remain on the periphery of Godin's book. However, his analysis shows a progressive erosion of the assumed importance of science among innovation practitioners. The linear model still conceptualises innovation as science applied, and thus considers science necessary and sufficient for technological innovation. Later conceptualisations focus more and more on meeting (market) demands, technology adoption and commercialisation. The book thus makes clear that there has long been scepticism among powerful innovation actors about the relative importance of science for the economy. With ongoing calls (especially from the OECD) to integrate science and innovation policy further, the book serves as a warning to scientists that such developments might challenge their societal legitimacy (and funding) if they do not pay close attention.

The main limits of this book arise inevitably out of Godin's choice to focus on meticulously documenting practitioner work on innovation. This gives us a clear, comprehensive and verifiable picture of the entities that have been involved in the technological innovation discourse, and the evolution of the discourse itself. However, it limits insight into the influence, power and contextual significance of those entities. Typical STS tools such as narrative research and sociotechnical imaginaries might carry their own risks when developing data into a coherent story, but I regularly found myself wondering which of the many reports had been more or less influential, and how, and why. When Godin draws wider causal or normative lessons from his findings, his claims are intriguing, but more as suggestions for further research than as arguments. For example, at the end of chapter 7, Godin warns that academics think about responsible, sustainable, etc. innovation as contestations of, and alternatives to, technological innovation (p. 139). However, policymakers are so entrenched in the technological innovation framework that they rather see such concepts as its extensions and legitimation. In this way, academics could unintentionally strengthen rather than contest the notion of technological innovation among practitioners. While this is a legitimate concern, the opposite could also be argued on the basis of Godin's data: that a concept such as responsible innovation has only been able to become influential among practitioners by engaging with the innovation discourse, where a different and more radical concept might not have gained any traction.

A similar limit is visible in the relation between science and innovation sketched in the book. Godin argues that "science policy has its historians (...) but innovation policy has none" (p. 143). Unfortunately, he does not draw on these historians to explain whether scientists and science policy have responded to the increasing marginalisation of science by innovation practitioners. More generally, it was not always clear to me whether the lack of interactions with non-practitioners in the book is due to its particular focus on the practitioner community, or whether such interactions had largely been absent.

To call these limits criticisms would not do justice to the book: it promises to be a historiography of the idea of technological innovation, and to show that practitioners rather than scholars have developed this idea. It fully delivers on both promises. Its empirical material is rich and detailed and the different conceptualisations of technological innovation are clearly described. As such, it is a valuable resource for STS scholars researching the concept of technological innovation, its significance, and its possible futures. Moreover, by showing the discourse's deep roots, its consistent focus on growth and competitiveness, and its movement away from fundamental science, the book cautions academics against optimism that developing concepts of 'responsible' or 'sustainable' innovation is itself enough to drastically reorient a discourse that has been developing continually, but always in fundamentally the same direction. 